\title{
A ECOSOFIA DE FÉLIX GUATTARI: UMA ANÁLISE DA FILOSOFIA PARA AS QUESTÕES AMBIENTAIS
}

\author{
Kellison Lima Cavalcante ${ }^{1}$
}

\begin{abstract}
Resumo: O conceito de Ecosofia foi criado pelo filósofo francês Félix Guattari, que expressa às formas como os sujeitos interagem entre si e com o meio ambiente. Com a Ecosofia é possível compreender que a natureza e os seres humanos fazem parte do mesmo ecossistema comunicativo, propondo assim, discussões entre meio ambiente e filosofia. Dessa forma, esse trabalho teve como objetivo refletir sobre o pensamento ecosófico, como um instrumento de conhecimento do sentido humano na natureza, através de uma discussão teórica do assunto abordado. Fundamentou-se a partir de aspectos provenientes dos pensamentos e registros de Félix Guattari, que contribuíram e auxiliaram na problematização da pesquisa. A Ecosofia proposta por Guattari aborda a nossa compreensão, como parte do meio em que vivemos, e como aprendemos e agimos sobre a problemática ambiental, tendo por base as três ecologias: a do meio ambiente, a das relações sociais e a da subjetividade humana (mental). Nesse sentido, os problemas ambientais são resultados da evolução da sociedade, em seus aspectos econômicos, políticos, sociais e educacionais, que sintetizam a subjetividade da condição humana. Assim, essa subjetividade significa a nossa percepção sobre o mundo em que vivemos e sobre nós mesmos, nosso modo de pensar e agir para preservar e cuidar do meio ambiente. De acordo com a Ecosofia proposta por Guattari, o que está em questão é a maneira de viver daqui em diante sobre esse planeta, no contexto da aceleração das mutações técnico-científicas e do considerável crescimento demográfico. Dessa forma, é possível compreender que a Ecosofia é mais que uma reflexão sobre ecologia, natureza e subjetividade humana, é uma busca por ações concretas, levando em consideração a interação do homem com o meio ambiente.
\end{abstract}

Palavras-chave: filosofia; ecologia; meio ambiente.

\section{THE ECOSOPHY OF FELIX GUATTARI: AN ANALYSIS OF PHILOSOPHY FOR ENVIRONMENTAL ISSUES}

\begin{abstract}
The concept of Ecosophy was created by the french philosopher Felix Guattari, who expresses the ways in which subjects interact with each other and with the environment. With Ecosophy it is possible to understand that nature and human beings are part of the same communicative ecosystem, thus proposing discussions between environment and philosophy. Thus, this work had as objective to reflect on the ecosophical thought, as an instrument of knowledge of the human sense in nature, through a theoretical discussion of the subject addressed. It was based on aspects derived from the thoughts and records of Félix Guattari, who contributed and helped in the problematization of the research. The Ecosophy proposed by Guattari addresses our understanding, as part of the environment in which we live, and how we learn and act on environmental issues, based on the three ecologies: the environment, social relations and human subjectivity (mental). In this sense, environmental problems are results of the evolution of society, in its economic, political, social and educational aspects, which synthesize the subjectivity of the human condition. Thus, this subjectivity means our perception about the world we live in and about ourselves, our way of thinking and acting to preserve and

${ }^{1}$ Graduando em Licenciatura em Filosofia (UFPI - Polo Juazeiro-BA), Mestre em Tecnologia Ambiental (ITEP/UFPE), e-mail: kellisoncavalcante@hotmail.com
\end{abstract}


care for the environment. According to Ecophotos proposed by Guattari, what is at stake is the way of living from now on on this planet, in the context of the acceleration of technical-scientific mutations and considerable population growth. In this way, it is possible to understand that Ecosophy is more than a reflection on ecology, nature and human subjectivity; it is a search for concrete actions, taking into account the interaction of man with the environment.

Keywords: philosophy; ecology; environment.

\section{INTRODUÇÃO}

A sociedade atual discute com frequência sobre as questões ambientais, destacando a preocupação na extinção dos recursos naturais, das várias formas de vida e o consequente fim da própria espécie humana no planeta. Isso se deve, principalmente, à crescente ação de deterioração da natureza, provocada pelo homem. Assim, a crise ambiental é resultado da nossa sociedade, que interfere na natureza, sem preocupar-se com o futuro.

Guattari (2009) afirma que os modos de vida humanos individuais e coletivos evoluem no sentido de uma progressiva deterioração do nosso planeta. Nesse sentido, os problemas ambientais da contemporaneidade são resultados das ações humanas sem projeção consciente ao longo do tempo, prejudicando o futuro da natureza. Assim, torna-se relevante a discussão ecosófica abordada pelo filósofo francês Félix Guattari, que procurou concatenar de modo lógico e heterogêneo os conceitos do que é natural e do que é cultural, relacionando natureza e meio ambiente com o humano.

De acordo com Guattari (2009), vivemos no planeta sob a aceleração das mutações técnico-científicas que podem ser identificadas no tempo atual, onde vivemos uma crise ambiental, de revoluções políticas, sociais e culturais. Através de três registros. Assim, a proposta ecosófica defendida por Guattari busca resposta e ações para a problemática ambiental que vivenciamos no cotidiano.

A tomada de consciência ecológica futura não deverá se contentar com a preocupação com os fatores ambientais, mas deverá também ter como objeto devastações ambientais no campo social e no domínio mental (GUATTARI, 2009, p. 41). Dessa forma, torna-se imprescindível a compreensão da formação do sujeito ambiental atualmente, inserido no processo de inclusão nas práticas ecológicas e ações ambientais para buscar soluções para as ações antrópicas de destruição. Assim, sem transformações das mentalidades e dos hábitos coletivos haverá apenas medidas ilusórias relativas ao meio material. 
Para Guattari (2009), a Ecosofia é um modelo prático e especulativo, ético-político e estético, não sendo uma disciplina, mas sim uma simples e eficaz renovação das antigas formas de concepção do ser humano, da sociedade e do meio ambiente.

Nesse sentido, essa pesquisa partiu da problemática que Guattari (2009) afirma que os modos de vida humanos individuais e coletivos evoluem no sentido de uma progressiva deterioração. Dessa forma, esse trabalho teve como objetivo refletir sobre o pensamento ecosófico, como um instrumento de conhecimento do sentido humano na natureza e a contribuição no processo de aprendizagem no mundo contemporâneo.

Assim, este trabalho caracteriza-se em uma pesquisa qualitativa, requerendo o uso do método exploratório e descritivo referente ao assunto em questão e abordagem teórica sobre a Ecosofia no processo de formação do sujeito ambientalmente consciente. Assim, consistiu em uma análise e interpretação dos aspectos provenientes do pensamento de Félix Guattari, que contribuiu e auxiliou na problematização.

\section{A ECOSOFIA}

O conceito de Ecosofia foi criado pelo filósofo francês Félix Guattari, que expressa as formas como os sujeitos interagem entre si e com o meio ambiente, a partir do conhecimento de práticas ambientais sustentáveis no processo inclusão do sujeito no meio ambiente e parte da natureza, para preservação e conscientização ambiental. De acordo com Guattari (2009) a Ecosofia aborda a nossa compreensão, como parte do meio em que vivemos, e como aprendemos e agimos sobre a problemática ambiental, tendo por base as três ecologias: a do meio ambiente, a das relações sociais e a da subjetividade humana (mental).

Ecologia do meio ambiente - onde tudo é possível de acontecer, quanto às evoluções flexíveis e quanto às piores catástrofes ambientais; "cada vez mais, os desequilíbrios naturais dependerão das intervenções humanas", principalmente quanto à regulação das relações entre o oxigênio, o ozônio e o gás carbônico; Ecologia social - deve trabalhar as relações humanas, reconstruindo-as em todos os níveis do socius; Ecologia subjetiva ou mental - será levada a reinventar a relação do sujeito como o corpo, a psique (inconsciência) e o consciente (GUATTARI, 2009, p. 52). 
O pensamento ecosófico consiste em despertar a condição humana no meio ambiente como consequência das nossas ações sem projeção consciente, que vêm ocorrendo ao longo das gerações e que culminaram nos graves desequilíbrios ecológicos da contemporaneidade, além de enfatizar a formação de um novo ser humano, com base nas três ecologias propostas pelo filósofo. Guattari (2009) ressalta que os modos de vida humanos individuais e coletivos evoluem no sentido de uma progressiva deterioração. Assim, o enfoque do pensamento do filósofo através da Ecosofia está no fracasso em entendermos e aprendermos sobre a problemática ambiental, sobre as ações que a causaram e suas implicações ou projeções ao longo do tempo.

Nesse sentido, os problemas ambientais são resultados da evolução da sociedade, em seus aspectos econômicos, políticos, sociais e educacionais, que sintetizam a subjetividade da condição humana. Assim, essa subjetividade significa a nossa percepção sobre o mundo em que vivemos e sobre nós mesmos, nosso modo de pensar e agir para preservar e cuidar do meio ambiente. De acordo com a Ecosofia proposta por Guattari, o que está em questão é a maneira de viver daqui em diante sobre esse planeta, no contexto da aceleração das mutações técnico-científicas e do considerável crescimento demográfico.

Assim, a Ecosofia consiste no entendimento e desenvolvimento de novas práticas sociais e analíticas na busca da criação de novas subjetividades. Como afirma Guattari (2006):

Não seria exagero enfatizar que a tomada de consciência ecológica futura não deverá se contentar com a preocupação com os fatores ambientais, mas deverá também ter como objeto devastações ambientais no campo social e no domínio mental. Sem transformações das mentalidades e dos hábitos coletivos haverá apenas medidas ilusórias relativas ao meio material (p.173).

Nessa perspectiva, de acordo com Devall e Sessions (2004), Sofia vem do grego 'sabedoria', o que relaciona com a ética, as normas, as regras e a prática, assim, a Ecosofia implica um deslocamento da ciência para a sabedoria. Assim, o que precisamos no mundo contemporâneo é a expansão do pensamento ecológico em direção ao pensamento da Ecosofia. A condição humana passa a ser um ser integrado no meio, um ser completo, holístico, que conjuga aspectos biológicos, mentais, sociais e espirituais.

A Ecosofia insere-se no contexto de uma força potencializadora e/ou uma ação para refletir sobre as problemáticas existentes no e pensar a educação e o meio ambiente, como destaca Guattari (2009):

A Ecosofia não considera a dimensão do meio ambiente como sinônimo de natureza coloca em igualdade a qualidade das relações sociais, bem como a qualidade da subjetividade humana, construídas a partir das relações do ser humano consigo mesmo, dos seres entre si, com o ambiente planetário (p. 32). 
Assim, as condições do meio ambiente não podem ser dissociadas da nossa condição de existência no planeta. Essa condição está associada diretamente a nossa formação ecológica, a nossa formação como um sujeito ambientalmente consciente. $O$ ser humano precisa aprender a desenvolver um pensamento transversal para compreender de fato e implantar em sua essência, a fim de entender as frágeis relações que regem os aspectos globais do nosso planeta, em uma esfera mais abrangente e os aspectos locais e pertinentes ao nosso desenvolvimento.

A Ecosofia tem como princípio a formação de cidadãos capazes de compreender o ambiente em que vivem e buscar respostas para os problemas de um modo geral, como éticos, científicos, culturais e, sobretudo ambientais. A Ecosofia tem como finalidade estimular o educando a observar e compreender o mundo, como sendo parte integrante dele, oferecendo assim, a possibilidade de agir, com respeito e consciência.

Dessa forma, as três ecologias descritas na Ecosofia de Félix Guattari tornam evidentes as problemáticas que estão acontecendo na nossa natureza, que exige cuidados especiais para poder preservar e criar condições para manter o equilíbrio do meio ambiente. Assim, a Ecosofia se configura como uma necessidade social, criando uma conscientização de que todos devem cuidar e preservar o meio ambiente para as futuras gerações, formando indivíduos atuantes.

De acordo com Guattari (2015), as três ecologias se unificam em um ponto comum, que consiste em liberar as antinomias de princípio entre os níveis ecosóficos. Assim, a Ecosofia seria a busca de uma dimensão ecossistêmica e não mais antropocêntrica das relações do homem com o meio ambiente, com a sua mente e com os outros humanos, em busca de respostas para as contradições das nossas ações. Dessa forma, consiste em compreender em dotar a humanidade de um fator incitador à práxis aberta e infinita, sem moldes, recortes ou singularidades (GUATTARI, 2015).

Nós dependemos do meio ambiente para nossa sobrevivência desde a evolução dos nossos ancestrais. Porém, como parte integrante da natureza e, sobretudo um ser social capaz de provocar alterações no meio em que vivemos, podemos a partir da Ecosofia, provocar mudanças permanentes para cuidar da nossa natureza.

De acordo com Gallo (2003), o gênero humano desenvolve de tal modo sua consciência no tempo que chega um momento onde não basta sentir o mundo criando valores (mitos) sobre o mundo. Surge o desejo de descobrir as leis que regem o nosso mundo, a querer entender o mundo de modo racional e procurar soluções para os problemas resultantes de nossas ações. Nesse sentido, é possível destacar que a filosofia se opõe ao mito, pois a consciência filosófica não se limita a sentir o mundo. Assim a Ecosofia tem como finalidade interpretar de modo 
racional os questionamentos e problemas do nosso meio ambiente para, em seguida, questionar a realidade.

Nessa perspectiva, o pensamento ecosófico de Guattari possibilita a relação do ser humano com a realidade que o produz e o atravessa, em suas múltiplas dimensões. Assim, através da compreensão das três ecologias torna-se imprescindível a nós, como seres humanos e parte indissociável do meio ambiente, a procura da conciliação dessa relação de possibilidade no nosso Planeta para minimizar os riscos de problemas ambientais e intervenções humanas na natureza.

\section{CONSIDERAÇÕES FINAIS}

A Ecosofia proposta por Guattari aborda a nossa compreensão, como parte do meio em que vivemos, e como aprendemos e agimos sobre a problemática ambiental, tendo por base as três ecologias: a do meio ambiente, a das relações sociais e a da subjetividade humana (mental). Assim, foi possível compreender que a ecologia ambiental tem como características a possibilidade de ocorrência naturalmente. A ecologia mental está relacionada aos conceitos de desempenho e benefício humano como ser ambiental e consciente. Dessa forma, a ecologia social tem como princípio o convívio humano em sociedade e a busca pela solução coletiva dos problemas ambientais tanto na esfera local como global.

A Ecosofia apresenta aspectos fundamentais para desvelar a relação que nós precisamos entender para a conscientização ambiental, garantindo a continuidade do mundo em que vivemos, preservando a natureza e os seres vivos. Foi possível compreender que a Ecosofia é mais que uma reflexão sobre ecologia, natureza e subjetividade humana, é uma busca por ações concretas, levando em consideração a interação do homem com o meio ambiente. Dessa forma, a Ecosofia estimula uma ampla consciência ambiental, possibilitando extrair do campo da aprendizagem e do conhecimento o potencial de nos tornarmos capazes de compreender o que o nosso planeta precisa e rever nossas ações. 


\section{REFERÊNCIAS}

DELEUZE, G.; GUATTARI, F. O que é a filosofia? Tradução de Bento Prado Jr. e Alberto Alonso Muniz. Rio de Janeiro: Ed. 34, 1992.

DEVALL, B.; SESSIONS, G. Ecologia profunda: dar prioridade à natureza na nossa vida. Águas Santas: Edições Sempre-em-Pé, 2004.

GALLO, S. Deleuze e a educação. Belo Horizonte: Autêntica, 2003.

GUATTARI, F. As três ecologias. 20ª ed. Trad. Maria Cristina F. Bittencourt. Campinas: Papirus, 2009, 56p.

Caosmose: um novo paradigma estético. $4^{a}$ reimpressão. Rio de Janeiro: Editora 34, 2006.

¿Qué es la ecosofía?: textos presentados y agenciados por Stéphane Nadaud. Ciudad Autónoma de Buenos Aires: Cactus, 2015. 448 p. 